\title{
The mediating effect of organizational factors between multidimensional performance measures and performance management systems
}

\author{
Kien Pham Van ${ }^{a}$, Phong Nguyen Dinh ${ }^{b}$, Tung Tran Anh ${ }^{c^{*}}$ and Linh Nguyen Tran Cam ${ }^{d}$
}

${ }^{a}$ Faculty of Commerce - Van Lang University, Vietnam

${ }^{b}$ Department of Leadership and Public Policy - Academy of Politics Region II, Vietnam

'School of International Education - Hong Bang International University, Vietnam

${ }^{d}$ Ho Chi Minh City Open University, Vietnam

\section{H R O N I C L E}

Article history:

Received: October 16, 2019

Received in revised format:

January 302020

Accepted: February 10, 2020

Available online:

February 10, 2020

Keywords:

Performance Management Sys-

tems

Organizational factors

Mediating Effect

Multidimensional Performance

Measures

\section{A B S T R A C T}

There are many studies on the effectiveness by employing management systems and this paper tries to point out the critical components that embodied the obstacles on system deployment on the context of the emerging markets in Viet Nam. The study is conducted as an exploratory research project which uses a quantitative approach to gain insight and information of the businesses in question. The data was collected via a survey questionnaire derived from experts and focus groups. The findings of this study indicated the significant role of organizational factors such as employee participation and communication, demonstrating they were critical mediators in the given context. Upon completion of the research, we advanced the study of these factors that directly and indirectly affect the success of PMS implementation throughout the empirical approach on Vietnamese firms.

O 2020 by the authors; licensee Growing Science, Canada

\section{Introduction}

In the new trend of management, the employee is the most critical asset of any organization (Tangen, 2004). All new entities expect to improve their employees' productivity by triggering their proactive and initiative behaviors, empowering responsibility for their professional development. To create a competitive environment and illustrate the fairness of appraisal, in recent years, many organizations have been trying to implement new or improve their performance management systems (PMS). Currently, the recent PMS literature has focused on the trend of implementing multidimensional PMS such as the Performance pyramid (Lynch \& Cross, 1991; Gupta \& Kumar, 2013), the Balanced Scorecard (Kaplan \& Norton, 1992), and the Performance Prism System (Neely et al., 2001), rather than the traditional one, which only focuses on the financial perspective. Besides this, there were only a limited number of empirical studies examining the direct effect of those trends on PMS. Nevertheless, the results from previous studies also indicated that the existing relationship between those contingency factors of multidimensional PMS and performance, such as the Balanced scorecard, was positive. In other words, unless the specific objectives of a firm were archived, such as employee performance and assessment with high accurate measurement or development in the employee's personal skills, then those factors of implementing multidimensional PMS would remain unseen. In addition, according to Farashahi et al. (2005), over the last twenty years, 95\% of empirical research grounded in institutional theory focused on developed countries rather than developing countries. As a result, there is a limited number of structural studies on institutional effects and changes in emerging countries although many of these countries offer a highly dynamic environment which is a good testing ground for a new theory, techniques, and concepts of business and management (Pacek

* Corresponding author

E-mail address: tungta@hiu.vn (T. Tran Anh)

C 2020 by the authors; licensee Growing Science, Canada doi: $10.5267 /$ j.msl.2020.2.015 
\& Thorniley, 2004). Due to the differences in working style, culture and development pace, some scholars doubt the feasibility of implementing existing Western management practices in emerging markets. Therefore, our research will attempt to provide businesses with empirical findings of what factors are influencing the effectiveness of PMS. From the results, this study will make some suggestions for business owners or boards of management to successfully implement new PMS or to improve the current one at their organization. This study was mainly conducted in the Ho Chi Minh Power Corporation (EVNHCMC) as well as 21 small-medium enterprises in Vietnam to obtain an understanding of management, and employees' perceptions about the implementation of PMS. Based on this feedback, the research can generalize the costs and benefits of applying PMS and suggest appropriate approaches to improve current systems.

\section{Literature review}

\subsection{Performance Management System (PMS)}

PMS is an integrated set of planning and review procedures which cascade down from the organization's strategy into individual objectives (Smith \& Goddard, 2002; Ochoti et al., 2012; Taylor \& Taylor, 2014). According to the summary of Hudson et al. (2001), there are 7 key aspects of procedures that mangers should consider while applying PMS in management, such as whether or not the procedure is derived from strategy, clearly defined with an explicit purpose, relevant and easy to maintain, simple to understand and use, provide fast and accurate feedback, link operations to strategic goals, and stimulate continuous improvement. In an organization, performance management is the most crucial process to attain a competitive advantage. Through PMS, an organization can communicate the vision and strategy to their employees effectively (Kaplan \& Norton, 1996). According to Lawson et al. (2003), more than two-thirds of 150 organizations agree that PMS helps employees become more aware of the company's strategy and business goals. PMS are also the most useful tools to align strategic objectives with operational improvements. In addition, an effective PMS helps remove the deficiencies that were found in previous systems. Business performance can be improved through PMS (Armstrong, 2006; Parmenter, 2015).

\subsection{Multidimensional performance management measures (MPM)}

Multidimensional measures enable organizations to have the overall strategic pictures which help managers know what needs improving (Ittner et al., 2003) and how to implement these initiatives (Stede et al., 2006). Therefore, a combination of leading and lagging indicators of the BSC approach is a useful way to enable management. According to Stede et al. (2006), the performance of an organization which extensively uses objective and subjective non-financial measures are found to be better than others. The use of the Balanced Scorecard (BSC) has been widely studied across different companies, industries and countries with different findings. Some researchers have proved the positive outcomes of applying the BSC. These studies have shown that the corporate strategy can be effectively aligned (Crabtree \& DeBusk, 2008; Braam \& Nijssen, 2004). BSC can lead to better satisfaction of the organization implementing PMS (Ittner et al., 2003). BSC is a useful tool to assess the strategy of the organization (Malina \& Selto, 2001). However, there are still disturbing findings that the outcomes of using the BSC is not always positive. Many firms have experienced failure during the implementation process and also believed that the long-term results would have not been realized (Niebecker et al., 2008). Fewer than 20\% of companies utilizing the BSC have realized measurable performance improvement (Williams, 2004). Buytendijk (2007) proposes that the perception that implementation of a BSC, in and of itself, will lead to organizational alignment is a "fairytale." Therefore, this study also aims to find the association between the BSC - a representative for multidimensional performance measures, and the effectiveness of the overall PMS. All of these studies have led to this first hypothesis:

$\mathrm{H}_{1}$ - The use of multidimensional performance measures has a positive impact on the effectiveness of the PMS.

\subsection{Organizational factor}

\subsubsection{Employee participation (EMP)}

The new management trend is empowerment. Managers have to give subordinates more space to develop ideas, execute plans, and be responsible for what they have done. Currently, there are many studies about such trends and their benefits (Morrell \& Wilkinson, 2002; Koberg et al., 1999; Chiles \& Zorn, 1995; Pun et al., 2002; Wimalasiri \& Kouzmin, 2000). Kleingeld et al. (2004) found that the higher the improvement in performance, the greater the level of involvement the employees had. To achieve the improvement, managers have to combine two mechanisms: cognitive (communication, utilization of knowledge and understanding) and motivational (resistance to change, commitment, acceptance goals, and feedback). To achieve better results, the employees at the bottom of the organizational chart also need to participate in the implementation process. They may not contribute much in the developing process, but the participation helps them understand that certain tasks cannot be done by others, except only themselves. In addition, giving chances to employees to express their ideas, are also good initiatives of management and allow them to have a better understanding about employees' concerns. This information is beneficial for managers when making decisions.

$\mathrm{H}_{2}$ - Employee participation has a positive impact on the effectiveness of the PMS. 


\subsubsection{Communication (COMM)}

Assaf and Agbola (2011) have identified that the effectiveness of communication within the system is a critical factor affecting the successful implementation of PMS. Supporting for these findings, Elliott (2011) emphasized that communication plays a vital role in any aspect of a business. Ineffective communication will lead to employee frustration and become a source of conflict. In contrast, effective communication will provide a clear understanding of company demands and employee expectations. Effective communication, then creates motivation for the staff and consequently increases customer loyalty and finally profits. Transparent and timely communication of performance expectations is a critical factor leading to the effectiveness of PMS in any organization. Similarly, providing continuous and contributive feedback is an integral part of communication.

$\mathrm{H}_{3}$ - Communication has a positive impact on the effectiveness of the PMS

\subsection{The mediating relationship between MPM and PMS}

According to Meekings (1995), successful implementation of PMS is determined less by setting the right measures but more by implementing and using the measures. Thereby, the involvement of not only employees, but also the management team to use these measures are critical factors leading to the success of the effectiveness of PMS (Franco \& Bourne, 2005; Chan \& Chan, 2004; Bourne et al., 2002; Dees et al., 2002; Kennerley \& Neely, 2002). Apparently, the effectiveness of PMS was dependent upon the organization consecutively developing and involving equivalently the self-renovation of all management levels from the top to bottom. Hence, a change in management is the most important and challenging process for any organizations. People only accept new changes whenever they understand the purpose and benefits of implementing the reforms. In other words, unless managers and employees communicate in one voice for the final objectives and visions, they are unlikely to commit or comprehend the process (Bourn, 2005; Chan \& Chan, 2004; Dees et al., 2002).

Therefore, the hypotheses are proposed as following:

$\mathrm{H}_{4}$ - Employee participation and Communication mediate the relationship between MPM and PMS.

$\mathrm{H}_{3}$

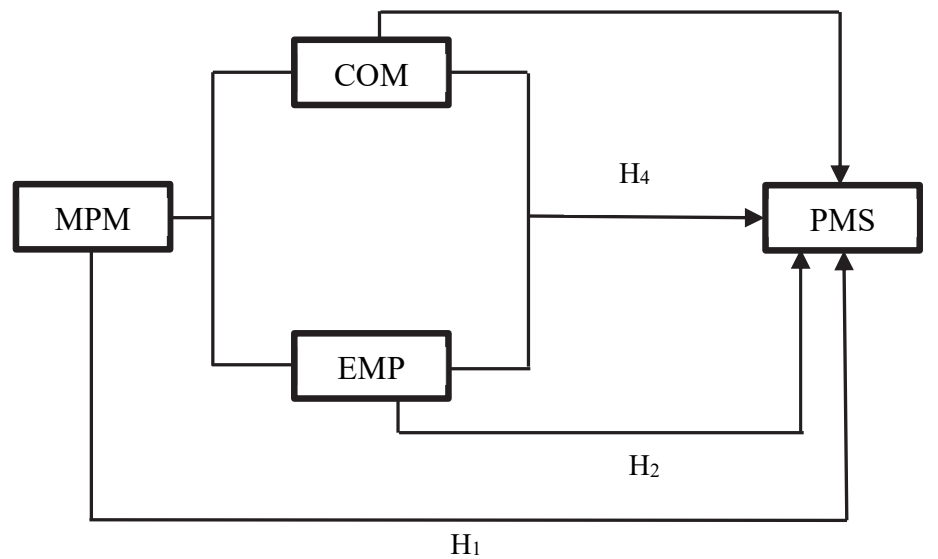

Fig. 1. Conceptual model

\section{Methodology}

\subsection{Research design and data collection}

There are several different techniques that can be employed and combined to collect data. Similarly, in this research, the insight collected from experts: board of directors, implementation team, and other heads of departments are significant. Therefore, in-depth interviews are conducted to receive feedback and insight for evaluating these top managers. For the quantitative method, this is the primary method to get the results from collecting data by conducting the survey. Data will be transformed into the final parameters for analysis by SPSS test and AMOS. According to Abimbola et al. (2010), the study employed the seven-point Likert scales to conduct the measurement scales in the questionnaire.

\subsection{Data collection and analysis}

\subsubsection{Data collection}

Hair (1998) suggested that "the numbers of collected data should be more than five times the numbers of observed variables." This determines that the minimum sample size is " $\mathrm{N} \geq 5$ multiply $\mathrm{X}$ " ( $\mathrm{N}$ is sample size; $\mathrm{X}$ is the total number of observed). Statistics for sample measurement in this study must own at least 180 respondents. Consequently, researchers estimated a 250 sample size required for this study. 


\subsubsection{Data analysis}

First and foremost, reliability tests desire to confirm or examine the consistency among various items in one concept by looking at Cronbach's alpha values ranging from 0.7 to above. Then came the EFA technique which in this process, the researcher can image the observed variables that lie on a structure and confirm which variable is out of the concept. For conducting factor analysis, these standards must fulfill following:

- Kaiser-Meyer-Olkin (KMO) must equal or exceed 0.6 (Pallant, 2005)

- Total Variance Explained cumulative must beyond 50\% for all extracted factors (Gerbing \& Anderson, 1998)

○ Factor loading must be from minimum at 0.3 to maximum at 0.5 (Hair et al., 1998; Byrne, 2001)

After conducting validity and reliability tests, the Confirmatory factor analysis (CFA) was applied to examine the model fit in this study. To run the CFA test, we first must have the results of the EFA, then the researcher takes the structure explored by the pattern matrix of EFA to CFA to verify this structure again and create the model fit among these factors. In short, "EFA explains how the theoretical specifications of the factors meets the original data" (Hair et al., 2010).

To get model fit, researchers will analyze these values such as CMIN/df, CFI, GFI, TLI, AGFI, RMR, and RMSEA. After CFA, Structural Equation Modeling (SEM) is used to investigate the relationship between independent factors and dependent factors and points out the direct or indirect influences if there are any to be observed of the relation among constructs. Furthermore, the fitness model needs satisfied with these Criteria CMIN/df, CFI, GFI, TLI, AGFI, RMR, RMSEA, and HOLTER as same as EFA criteria

\section{Findings}

\subsection{Reliability and Validity Test}

Table 1

$\underline{\text { Reliability and Validity measurement }}$

\begin{tabular}{|c|c|c|c|c|c|c|}
\hline VARIABLE & ITEMS & EFA LOADINGS & CFA LOADINGS & MEAN & SD & $\begin{array}{c}\text { CRONBACH'S } \\
\text { ALPHA (A) }\end{array}$ \\
\hline \multirow[t]{4}{*}{ МРM } & MPM2 & 0.722 & 0.74 & 4.794 & 0.047 & 0.78 \\
\hline & MPM3 & 0.75 & 0.64 & & & \\
\hline & MPM4 & 0.73 & 0.76 & & & \\
\hline & MPM5 & 0.62 & 0.48 & & & \\
\hline \multirow[t]{5}{*}{ COMM } & COMM1 & 0.62 & 0.61 & 4.755 & 0.02 & 0.732 \\
\hline & COMM2 & 0.45 & 0.57 & & & \\
\hline & COMM3 & 0.65 & 0.51 & & & \\
\hline & COMM4 & 0.73 & 0.66 & & & \\
\hline & COMM5 & 0.78 & 0.62 & & & \\
\hline \multirow[t]{3}{*}{ EMP } & EMP1 & 0.73 & 0.73 & 4.79 & 0.007 & 0.742 \\
\hline & EMP2 & 0.67 & 0.55 & & & \\
\hline & EMP3 & 0.68 & 0.73 & & & \\
\hline \multirow[t]{3}{*}{ PMS } & PMS1 & 0.6 & 0.77 & 4.93 & 0.003 & 0.714 \\
\hline & PMS2 & 0.742 & 0.66 & & & \\
\hline & PMS3 & 0.727 & 0.7 & & & \\
\hline \multicolumn{2}{|c|}{ INSTRUMENT TOTAL } & KMO & & & 0.89 & $\mathrm{p}<0.000$ \\
\hline
\end{tabular}

According to Table 1, the reliability test observes all constructs individually, as a result, all Cronbach's Alpha is higher than 0.8 , and all the values of corrected item-total correlation is beyond 0.5 . Totally, all scales of construct have an internal coefficient at elevated levels. In addition, the KMO index is 9.39, greater than 0.6 and the Bartlett's test is lower than 0.05 which led to the conclusion of meeting the requirement in validity of data.

Table 2

$\underline{\text { Discriminant validity test }}$

\begin{tabular}{ccccc}
\hline & CR & AVE & MSV & Max r \\
\hline MPM & 0.83 & 0.567 & 0.130 & 0.360 \\
COMM & 0.82 & 0.500 & 0.434 & 0.659 \\
EMP & 0.840 & 0.569 & 0.44 & 0.659 \\
PMS & 0.82 & 0.695 & 0.130 & 0.360 \\
\hline
\end{tabular}

Note: CR $>0.7 ;$ AVE $>0.5 ;$ MSV $<$ AVE; $\sqrt{A V E}>$ Max r, $\sqrt{A V E}$

The study conducts tests of convergent and discriminant validity. Indicators, in regards to CR (Composite Reliability) and AVE (Average Variance Extracted), are the components of the extent to which particular variables share a high ratio of common variance. As a result, in table I, CR demonstrates the value greater than 0.8 and AVE is greater than 0.5 , therefore, they serve the criteria of convergence among variables (Anderson \& Gerbing, 1988; Fornell \& Larcker, 1981). Otherwise, there are several measures contributing to justify the validity and reliability such as MSV (maximum shared variance), and MaxR (maximum reliability). According to Fornell and Larcker, the value of MSV should be lower than AVE, obviously, the result in table 2 indicates the requirements of validity and reliability are served. 


\subsection{Model fit and Mediating Test}

Table 3

Model fit indices of measurement model

\begin{tabular}{ccccc}
\hline Indices & Criteria & Model & \\
\hline$\chi^{2} / \mathrm{df}$ & $<3$ & 1.63 & \\
GFI & $>0.8$ & 0.94 & 0.94 \\
CFI & $>0.9$ & 0.91 & 0.91 \\
TLI & $>0.9$ & 0.95 & 0.95 \\
RMSEA & $\leq 0.08$ & 0.045 & 0.045 \\
\hline
\end{tabular}

Table 3 indicated that model fit indices of model and CFA had served all the criteria accordingly to the given threshold.

Table 4

Mediating test result

\begin{tabular}{|c|c|c|c|c|c|}
\hline Step & Predictor & Mediator & Outcome & Std. $\beta$ & Mediation of Organizational factors \\
\hline 1 & MPM & No & PMS & $0.272 \mathrm{NS}$ & Possible \\
\hline 2 & EMP & No & PMS & $0.209^{*}$ & Possible \\
\hline 3 & COMM & No & PMS & $0.358 * * *$ & Possible \\
\hline 4 & MPM & EMP and COMM & PMS & $\begin{array}{c}0.209 * \\
0.317 * * \\
0.206 \mathrm{NS}\end{array}$ & Occurred \& Accepted \\
\hline
\end{tabular}

In Table 4, the hypotheses 2, 3 and 4 are accepted, which prompts us to recognize the existence of a relationship among MPM, EMP, COMM and PMS. Narratively, organizational factors had a significant effect on the effectiveness of performance management systems and its measurement components, eventually, they proved that the mediation approach had been obvious in this case.

\section{Conclusion}

The main purpose of this research was to define the role of organizational factors on the effectiveness of current PMS in Viet Nam's context. Before going through these factors, research also collected the understanding of all levels of management in each firm regarding what a good PMS is and whether their current PMS is effective. To get the answers for the aims of the research, 4 hypotheses have been developed and tested to define the critical factors associated with the success of PMS implementation. After testing, three hypotheses have been accepted, and 1 other was failed to prove the significant impact. A good PMS need to clarify jobs, functions, and responsibilities; this is a must to have a practical and applicable engagement process regarding communication and employee participation to get them to understand and follow the directions of the organization. Therefore, corporations, especially leaders or deployment teams should create many creative approaches to communicate the right messages to all personnel in order to deliver basic knowledge about the nature and benefits of performance management systems for themselves, their departments, their organizations. For high level of management, there are approaches for Boards of Directors to change the current status and ensure better results for deploying PMS that:

- Develop a creative communication plan with various methods to improve the awareness of employees. Directors of subsidiaries can create internal seminars or meetings to explain the questions of employees in all levels in coordination with consultants to help them release all worries and stresses.

\section{References}

Abimbola, T., Lim, M., Foster, C., Punjaisri, K., \& Cheng, R. (2010). Exploring the relationship between corporate, internal and employer branding. Journal of Product \& Brand Management, 19(6), 401-409.

Anderson, J., \& Gerbing, D. W. (1988). Structural equation modeling in practice: A review and recommended two-step approach. Psychological Bulletin, 103(3), 411 423. https://doi.org/10.1037/0033-2909.103.3.411

de Waal, A. A. (2002). The role of behavioural factors in the successful implementation and use of performance management systems. Performance Measurement and Management: Research and Action, Centre for Business Performance, Cranfield School of Management, Cranfield, 157-64.

Armstrong, M. (2006). A handbook of human resource management practice. Kogan Page Publishers.

Assaf, A. G., \& Agbola, F. W. (2011). Modelling the performance of Australian hotels: a DEA double bootstrap approach. Tourism Economics, 17(1), 73-89.

Bourne, M. C. S., Mills, J. F., Wilcox, M. \& Neely, A. D. \& Platts, K, W., (2000). Designing, implementing and updating performance measurement systems. International Journal of Production and Operations Management, 20(7), 754-771.

Braam, G. J., \& Nijssen, E. J. (2004). Performance effects of using the balanced scorecard: a note on the Dutch experience. Long Range Planning, 37(4), 335-349.

Buytendijk, F. A. (2007). Challenging conventional wisdom related to defining business metrics: A behavioral approach. Measuring Business Excellence, 11(1), 20-26.

Byrne, B. M. (2001). Structural Equation Modeling with AMOS: Basic Concepts, Applications, and Programming. Mahwah, NJ: Lawrence Erlbaum Associates.

Chan, A. P., \& Chan, A. P. (2004). Key performance indicators for measuring construction success. Benchmarking: An International Journal, 11(2), 203-221. 
Chiles, A. M., \& Zorn, T. E. (1995). Empowerment in organizations: Employees' perceptions of the influences on empowerment. https://doi.org/10.1080/00909889509365411

Crabtree, A. D., \& DeBusk, G. K. (2008). The effects of adopting the balanced scorecard on shareholder returns. Advances in Accounting, 24(1), 8-15.

Dees, J. G., Emerson, J., \& Economy, P. (2002). Enterprising nonprofits: A toolkit for social entrepreneurs (Vol. 186). John Wiley \& Sons.

Elliott, J. (Ed.). (2011). Reconstructing teacher education (Vol. 221). Routledge.

Ernest, P. (1991). The philosophy of mathematics education. London: Falmer

Farashahi, M., Hafsi, T., \& Molz, R. (2005). Institutionalized norms of conducting research and social realities: a research synthesis of empirical works from 1983 to 2002. International Journal of Management Reviews, 7(1), 1-24.

Ochoti, G. N., Maronga, E., Muathe, S., Nyabwanga, R. N., \& Ronoh, P. K. (2012). Factors influencing employee performance appraisal system: a case of the ministry of state for provincial administration \& internal security, Kenya. International Journal of Business and Social Science, 3(20), 37-46.

Gupta, V., \& Kumar, S. (2013). Impact of performance appraisal justice on employee engagement: a study of Indian professionals. Employee Relations, 35(1), 61-78. Web.

Hair, J. F., Anderson, R. E., Tatham, R. L., \& Black, W. C. (1998). Multivariate data analysis 5th ed. New Jersey, NJ: Printice-Hall.

Hudson, M., Smart, A., \& Bourne, M. (2001). Theory and practice in SME performance measurement systems. International Journal of Operations \& Production Management, 21(8), 1096-1115.

Ittner, C. D., \& Larcker, D. F. (2003). Coming up short on nonfinancial performance measurement. Harvard Business Review, 81(11), 88-95.

Kaplan, R. S., \& Norton, D. P. (1996a). Using the Balanced Scorecard as a strategic management system. Harvard Business Review, 74(1).

Kaplan, R.S., \& Norton, D.P. (1996). Balanced Scorecard: Translating Strategy into Action. Harvard Business School Press, Boston, MA.

Kennerley, M., \& Neely, A. (2003). Measuring performance in a changing business environment. International Journal of Operations \& Production Management, 23(2), 213-229.

Koberg, C. S., Boss, R. W., Senjem, J. C., \& Goodman, E. A. (1999). Antecedents and outcomes of empowerment: Empirical evidence from the health care industry. Group \& Organization Management, 24(1), 71-91.

Lawson, T. (2003). Reorienting economics (Vol. 20). Psychology Press.

Lynch, R. L., \& Cross, K. F. (1991). Measure up!: The essential guide to measuring business performance. Mandarin.

Malina, M. A., \& Selto, F. H. (2001). Communicating and controlling strategy: An empirical study of the effectiveness of the balanced scorecard. Journal of Management Accounting Research, 13(1), 47-90.

Meekings, A. (1995). Unlocking the potential of performance measurement: A practical implementation guide. Public Money \& Management, 15(4), 5-12.

Morrell, K., \& Wilkinson, A. (2002). Empowerment: through the smoke and past the mirrors?. Human Resource Development International, 5(1), 119-130.

Neely, A., Adams, C., \& Crowe, P. (2001). The performance prism in practice. Measuring business excellence, 5(2), 6-13.

Niebecker, K., Eager, D., \& Kubitza, K. (2008). Improving cross-company project management performance with a collaborative project scorecard. International Journal of Managing Projects in Business, 1(3), 368-386.

Pacek, N., \& Thorniley, D. (2004). Emerging Markets: Lessons for Business Success and the Outlook for Different Markets (London: The Economist in association with Profile Books).

Parmenter, D. (2015). Key performance indicators: developing, implementing, and using winning KPIs. John Wiley \& Sons.

Pun, K. F., Hui, I. K., Lau, H. C., Law, H. W., \& Lewis, W. G. (2002). Development of an EMS planning framework for environmental management practices. International Journal of Quality \& Reliability Management, 19(6), 688-709.

Smith, P. C., \& Goddard, M. (2002). Performance management and operational research: a marriage made in heaven?. Journal of the Operational Research Society, 53(3), 247-255.

Stede, W. A. V. D., Chow, C. W., \& Lin, T. W. (2006). Strategy, choice of performance measures, and performance. Behavioral research in accounting, 18(1), 185-205.

Tangen, S. (2004). Performance measurement: from philosophy to practice. International journal of productivity and performance management, 53(8), 726-737.

Taylor, A., \& Taylor, M. (2014). Factors influencing effective implementation of performance measurement systems in small and medium-sized enterprises and large firms: a perspective from Contingency Theory. International Journal of Production Research, 52(3), 847-866.

Williams, R. (2004). Television: Technology and cultural form. Routledge.

Wimalasiri, J. S., \& Kouzmin, A. (2000). A comparative study of employee involvement initiatives in Hong Kong and the USA. International Journal of Manpower, 21(8), 614-634.

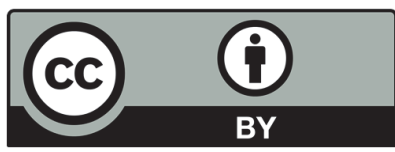

(C) 2020 by the authors; licensee Growing Science, Canada. This is an open access article distributed under the terms and conditions of the Creative Commons Attribution (CC-BY) license (http://creativecommons.org/licenses/by/4.0/). 